\title{
Redes latinoamericanas de arte constructivo
}

\section{Rossi, María Cristina}

Resumen:

Los proyectos de arte constructivo que surgieron en América Latina desde la inmediata posguerra fueron conformando una densa red de contactos, que muestra plataformas comunes -como el caso del estancamiento de los sistemas locales de formación artística-, e invita a explorar intercambios entre artistas y las particularidades con las que se reactivaron las estrategias de las vanguardias en diferentes escenas. Redibujar esa trama, entonces, permite visualizar rupturas y continuidades. Asimismo, dentro de los límites impuestos por este mapeo, se revisan algunos casos que reflejan los retos a los que están sometidas las producciones de los artistas latinoamericanos en el marco de la

Cuadernos del Centro de Estudios de Diseño y Comunicación N N 60

\begin{tabular}{|l|l}
\hline ISSN: 1668-0227 & $\begin{array}{l}\text { Lecturas y poéticas } \\
\text { del arte }\end{array}$ \\
latinoamericano: & $\begin{array}{l}\text { apropiaciones, } \\
\text { rupturas y } \\
\text { continuidades }\end{array}$ \\
Año XVII, Diciembre 2016, Buenos Aires,
\end{tabular}
Argentina | 176 páginas

descargar PDF ver índice de la publicación

Ver todos los libros de la publicación

compartir en Facebook

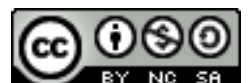

Esta obra está bajo una Licencia Creative Commons Atribución-NoComercialCompartirlgual 4.0 Internacional creciente complejidad del sistema artístico y de la lógica de la mundialización del capital.

Palabras clave:

arte latinoamericano - arte constructivo - arte concreto - arte no figurativo - arte nuevo - abstracción geométrica vanguardia/neo-vanguardia - cinetismo - integración de las artes.

(*) Doctora en Historia y Teoría del Arte (UBA). Profesora e Investigadora especializada en arte latinoamericano, área en la que enseña en la UBA y la UNTREF. Se desempeña como curadora independiente. Participa en libros y revistas nacionales e internacionales. Es miembro del Centro Argentino de Investigadores de Arte CAIA y de la Asociación Argentina e Internacional de Críticos de Arte (AACA y AICA).

Las propuestas de los artistas latinoamericanos que trabajaron en la vertiente constructiva conforman un capítulo reconocido por las historias del arte, especialmente, si se tiene en cuenta que la tendencia ha sido validada por innumerables exposiciones y por la creciente estimación del mercado del arte internacional. Sin 
embargo, la valoración de sus aportes y su inscripción en los espacios de negociación aún reclama miradas que intenten desarticular algunas lecturas cristalizadas y comiencen a echar luz sobre las particularidades.

El período de posguerra abrió un período en el cual los artistas latinoamericanos se volcaron hacia un arte moderno de base constructiva e, incluso, imaginaron -y formularon- programas utópicos. Sus obras dieron una forma y un sentido particular al momento inaugural del que fueron partícipes.

Sin duda, el último tramo de la Segunda Guerra Mundial generó una plataforma que -para un continente que no había sido parte de los escenarios de combate- presentaba parámetros comunes, aun considerando las distintas posiciones adoptadas1. El recrudecimiento de los fascismos, la Guerra Civil Española y la II Guerra Mundial provocaron un trauma de carácter histórico que, paradójicamente, coincidió con el entusiasmo por los avances de la ciencia y el salto tecnológico, que en gran medida había impulsado la misma maquinaria bélica. Además, estos sucesos tendieron a estimular las prácticas políticas que los más jóvenes canalizaron, en primer término, a través de las organizaciones estudiantiles y, luego, algunos volcaron hacia la militancia partidaria y el activismo en los frentes antifascistas.

Un mapeo de las producciones que fueron surgiendo en las distintas regiones permite entenderlas en el marco de las rupturas con las tradiciones locales $\mathrm{y}$, al mismo tiempo, muestra puntos de contacto e intereses comunes entre ellas. Nos preguntamos en primer término: ¿cuáles fueron sus escenarios de emergencia?, ¿qué fuerzas los impulsaron?, ¿cómo se activaron los vínculos entre los artistas? o ¿qué tipo de intercambios lograron realizar? Vanguardias situadas

\section{La irrupción rioplatense}

Promediando 1945 Europa debía enfrentar las pérdidas provocadas por la guerra, debía administrar el proceso de reconstrucción material y tramitar las secuelas del trauma histórico.

América Latina no contaba pérdidas humanas y en la inmediata posguerra las economías de algunos de sus países estaban en condiciones de ser proveedores de las potencias mundiales en vías de reconstrucción. Este escenario habilitaba la emergencia de una visión optimista para los jóvenes rioplatenses que, afirmados en la confianza en la racionalidad y la ciencia, se propusieron canalizar la idea de "júbilo creador" hacia la "invención" de formas concretas, mediante las cuales entendían que el hombre podría establecer una nueva relación con su entorno. (Imagen 1, 2 y 3) Se trataba de una propuesta que se oponía al imaginario figurativo dominante y con el cual, además, consideraban que lograrían recuperar la función transformadora del arte.

Con cabecera en las ciudades de Montevideo y Buenos Aires, estos jóvenes comenzaron a establecer contacto con los artistas e intelectuales latinoamericanos interesados en intervenir sobre sus realidades locales.

Aunque la mayor parte de los relatos acuerdan en ubicar el punto de partida de la vanguardia de arte concreto en 1944, con la aparición de Arturo. Revista de artes abstractas, prefiero partir en 1942 para enfocar la rebelión estudiantil del pequeño grupo que suscribió el Manifiesto de cuatro jóvenes (Jorge Brito, Alfredo Hlito, Claudio Girola y Tomás Maldonado). Con sus acciones, estos alumnos se pronunciaron no sólo contra el sistema de consagración, sino también contra sus maestros que habían actuado como jurados o habían sido premiados. Si bien el grupo intentó sumar a todo el alumnado para profundizar la protesta contra el sistema de enseñanza 
artística, no lograron la adhesión colectiva y la radicalización de su postura los condujo a abandonar las aulas (Rossi, 2010).

Este punto de partida no sólo permite identificar la conducta rebelde de los estudiantes frente al atraso de los programas de enseñanza artística como un denominador común entre las distintas escenas de América Latina, sino que también constituye un nodo configurador de vinculaciones entre artistas de las diferentes regiones. Tal es el caso del rechazo a los métodos de enseñanza de Escuela de Artes Plásticas y Artes Aplicadas de Caracas o del impulso reformador de la Escuela de Arquitectura de la Universidad Católica de Valparaíso, que trataré más adelante.

De hecho, la rebelión de los "cuatro jóvenes" argentinos coincidió con una exposición de Joaquín Torres García, presentada en la Galería Müller de Buenos Aires en septiembre de 1942. El maestro uruguayo representaba una alternativa de cambio, especialmente por su perspectiva de enseñanza antiacadémica y por sus vinculaciones con las vanguardias europeas.

Esta exhibición despertó entusiasmo entre los estudiantes porteños; sin embargo, mientras Brito decidió viajar a Montevideo para tomar contacto directo, sus compañeros comenzaron a discutir algunos aspectos de la pintura que se presentaba en esa exposición.

El regreso de Torres García a Montevideo había sido saludado con los mejores auspicios; no obstante, su arte constructivo pronto suscitó resistencias en la crítica y el público más tradicional. De todos modos, muchos artistas activos adoptaron sus postulados, en 1935 integraron la Asociación de Arte Constructivo y, al año siguiente, comenzaron a editar la revista Círculo y Cuadrado. En sus páginas se definía el concepto de construcción como una "estructura" en la que el símbolo -síntesis de la idea universal- alcanzaba el orden superior por medio de la medida y la proporción que regía al conjunto. Las polémicas y las fluctuaciones entre las dos líneas de arte que practicaba Torres García (una figurativa - aunque no imitativa- y otra esquemática), lo llevaron a ciertos momentos de escepticismo e interrupción de la enseñanza2.

Sin embargo, al finalizar la exposición de la Galería Müller, se manifestó interesado en volver a enseñar, aunque entendió que esta vez sólo sería posible impulsar sus ideas a través de los más jóvenes, es decir, aquellos a quienes debería formar desde cero y, entonces, fundó el Taller Torres García. En este momento de apertura de sus espacios de interlocución, también se habían acercado otros jóvenes, como los que en julio de 1942 emprendieron el proyecto de la revista uruguaya Apex, para la cual Torres entregó tanto el texto como los dos poemas que, después, también entregó a Carmelo Arden Quin para publicar en Arturo. El colectivo editor de esta revista de artes abstractas se completaba con Gyula Kosice, Edgar Bayley y Rhod Rothfuss, a quienes se sumaron como ilustradores Tomás Maldonado y Lidy Prati.

En abril de 1944, esta publicación marcó el momento de aparición de una propuesta de carácter invencionista que, desde la dialéctica marxista, se proponía arrasar con el primitivismo, el realismo y el simbolismo. Hacia fines de ese año, otro grupo editorial en el que se contaban varios militantes comunistas comenzó a publicar la revista Contrapunto, que intentaba reflejar los matices que se ocultaban entre las posiciones más extremas.

Entre otros temas, Contrapunto difundió la "Defensa del Realismo" que Héctor P. Agosti -un intelectual orgánico del Partido Comunista Argentino (PCA)- había escrito en su exilio montevideano. Fiel a la idea de contraponer 
ideas, la revista publicó un artículo del joven Raúl Lozza contra la postura de Agosti y cedió una doble página para que el crítico Roger Plá abriera la encuesta “¿Adónde va la pintura?”, en la que cada número reunía la opinión de artistas destacados. La primera entrega enfrentó la posición de Antonio Berni -el maduro cultor del nuevo realismo- y la del joven Maldonado, en cuya respuesta se anticipó el programa estético del arte concreto, mientras que en otro número se publicó la opinión de Manuel Espinosa ilustrada con una obra de marco recortado, cuya silueta se contraponía a la pintura "Mesa blanca" del ya consagrado Emilio Pettoruti.

Estas polémicas fueron afirmando las tomas de posición de los grupos de arte concreto mientras estaban formulando su propuesta en términos vanguardistas y activaron las prácticas de rigor: manifiestos, volanteadas, expresiones polémicas y otras estrategias de difusión de sus ideas, incluida la excepcional difusión del programa del arte concreto desde las páginas del periódico comunista Orientación, ya que el grupo había adherido a ese partido.

En este punto resulta interesante destacar que ni éstas fueron las primeras obras no figurativas que circularon en Buenos Aires, ni la encuesta fue el primer debate al respecto. La Primera exposición de Dibujos y Grabados Abstractos exhibida en la galería Moody en 1936, ya había generado un fuerte cruce de opiniones entre los críticos Julio Rinaldini y Attilio Rossi. No obstante, tal como plantea Pierre Bourdieu: Para que las osadías de la búsqueda innovadora o revolucionaria tengan posibilidades de ser concebidas, tienen que existir en estado potencial en el seno del sistema de posibilidades ya realizadas [...] más aún, hace falta que tengan posibilidades de ser recibidas, es decir, aceptadas y reconocidas como razonables. (Bourdieu, 1995, p. 349) Esta consideración es aplicable también a muchas otras producciones tempranas, como el caso de los "decembristas", grupo de artistas chilenos que presentaron la primera exposición de arte abstracto en diciembre de 1933, impulsados por el retorno del poeta Vicente Huidobro y sus ideas creacionistas (Lizama, s-f) pero que, sin embargo, no lograron darle continuidad.

En 1946 del grupo nucleado alrededor de Arturo, surgieron la Asociación de Arte Concreto Invención (AACl) y el grupo MADI3. En los primeros tiempos los dos grupos crearon obras de "marco recortado", (Imagen 4) cuyo borde se adaptaba a las formas irregulares que contenía y jugaba un rol activo en la composición. También realizaron "co-planares", para los cuales pintaban las formas sobre madera, las recortaban y unían con varillas para colocarlas directamente sobre el muro, también con función activa. Sin embargo, mientras los integrantes de la $\mathrm{AACl}$, fijaban las articulaciones cuando lograban la conformación adecuada4 (Imagen 1), los artistas madí dejaban que las varillas se movieran para permitir la intervención del espectador en la modificación de la forma5 (Imagen 5). La AACI, por su parte, suscribió un programa que aspiraba a rodear a los hombres de "cosas reales", porque sostenían que al evitar la "imitación" de la realidad habituarían al hombre a relacionarse "directamente" con las cosas en lugar de sus "ficciones" y, en términos dialécticos, lograrían una "voluntad de acción" capaz de provocar la transformación social.

En este clima de rupturas, entre octubre-noviembre de 1946 el artista ítalo-argentino Lucio Fontana discutió con sus alumnos de la Escuela Nacional de Bellas Artes "Manuel Belgrano" las ideas con las que escribieron el Manifiesto Blanco. El texto abogaba por la "superación de la pintura y la escultura para acceder a un nuevo arte de materia, color, sonido y movimiento" y fue suscripto sólo por los alumnos, ya que el profesor no figura entre los firmantes. De hecho, la producción de Fontana en ese momento no era abstracta; sin embargo, este manifiesto no sólo fue importante para la escena argentina, sino también para el posterior Manifiesto 
Espacialista firmado por Fontana, así como para la producción que realizó en Milán, que ya en 1949 desembocó en obras como Ambiente espacial con luz negra.

En los grupos de la vanguardia rioplatense se generaron sucesivas escisiones provocadas tanto por la radicalidad de los programas, como por los conflictivos liderazgos. De todos modos, simultáneamente, comenzó un proceso de expansión y reagrupamiento que en octubre de 1947 reunió en el Salón Kraft a unos cincuenta jóvenes que abogaban por el "arte nuevo", con una declaración colectiva que expresaba el deseo de unir a diferentes grupos para una acción de conjunto, con la intención de lograr un movimiento más amplio. Esta declaración también suscribía que las influencias de las escuelas europeas no habían entorpecido el desarrollo de las propuestas locales, sino que habían sido la "base para hallazgos y realizaciones completamente inéditos". Recuperar este marco histórico nos permite analizar los intercambios en el "período heroico" del arte concreto (1945-48), así como repensar las continuidades en las que su propuesta se expandió y diversificó.

Además, para 1948 la reconstrucción de posguerra ya permitía volver a planear recorridos por los museos y talleres europeos: Maldonado, Arden Quin, Juan Melé y Gregorio Vardanega se contaron entre los primeros en viajar. Estos intercambios coincidieron con la exigencia comunista de realineamiento sobre el canon del realismo socialista, situación que tensó las discusiones partidarias. En este marco, se quebró la tolerancia que el PCA había mostrado hacia los jóvenes concretos6. Si bien fueron muchos los factores que contribuyeron al desmembramiento de los grupos iniciales, para quienes habían considerado primordial unir la transformación política a la estética, esta nueva ruptura no sólo profundizó la tendencia a la dispersión grupal sino que también provocó la declinación de la utopía sostenida en ese período heroico.

\section{Conexiones tempranas}

Entre las conexiones significativas de la etapa expansiva, el caso más conocido en las cronologías es la temprana llegada del arte Madí a París, mediante el esfuerzo de divulgación de Kosice y el intercambio directo de Arden Quin, quien a través de Mateo Manaure y Luis Guevara Moreno, estuvo en contacto con el círculo de venezolanos que editó la revista Los disidentes (Imagen 7). También en 1949 la 1 re Exposition des Artistes d'Amérique-Latine à Paris fue un punto de encuentro para las obras de Vardánega, Melé, Arden Quin, Manaure y Narciso Debourg, entre otros.

Pero al situar a estos jóvenes venezolanos, es necesario considerar la rebelión de los estudiantes caraqueños disconformes con la enseñanza que habían abandonado la Escuela de Artes Plásticas y Artes Aplicadas en 1945. En primer término los alumnos fundaron la Barraca de Maripérez y, en 1948, crearon el Taller Libre de Pintura, donde trabajaban, discutían y exhibían sus nuevas propuestas. José Mimó Mena había compartido con los artistas concretos algunas exposiciones, como el Salón de Otoño que organizaba la Sociedad Argentina de Artistas Plásticos (SAAP). Al viajar a Venezuela, llevó un conjunto de obras que exhibió, precisamente, en ese

Taller Libre de Pintura en octubre de ese año. La presentación tomaba el concepto de "júbilo creador" que había enarbolado la vanguardia rioplatense, señalando: "en estas obras no hay tristeza, pintamos con juventud y alegría, no hacemos nada dramático, nos asustan los monstruos, para una civilización feliz, hacemos una pintura jovial" 7 .

Entre los alumnos rebeldes se contaban Manaure, Alirio Oramas, Rubén Núñez, y muchos otros. Me interesa subrayar la coincidencia referida al malestar de los más jóvenes y la ruptura con la Institución porque estos 
contactos recuperan puntos de convergencias entre proyectos artísticos, desde mi punto de vista más significativos que una mera cadena de influencias. En una recorrida por la historiografía venezolana, esta llegada del arte concreto argentino fue destacada por Bélgica Rodríguez (1979) y Adolfo Wilson (2007, pp. 15357), mientras que Ariel Jiménez ha desestimado su importancia porque considera que para los venezolanos como para los argentinos- la fuente de legitimación provenía de Europa y, en consecuencia, entiende que el impulso llegó a Caracas con la muestra Las cafeteras de Alejandro Otero (Cruz Diez-Jiménez, 2010, p. 157-8).

Dado que a través de la lectura de otros documentos surge que el mismo Otero no sólo recordó la exposición de los argentinos, sino que había colaborado en su organización (Melé 1999, pp. 126-30), considero que estos intercambios entre artistas y sus producciones son mucho más porosos que lo que puede mostrar una secuencia cronológica. En este sentido, rescato el valor de la convergencia de deseos y expectativas capaces de motivar nuevas propuestas, especialmente teniendo en cuenta que la proximidad entre la llegada de Mimó Mena en 1948 y Las cafeteras en 1949 habilita a pensar con Bourdieu, que las rupturas de un arte abstracto ya podían tener posibilidades de ser recibidas, aceptadas y reconocidas como 'razonables', por lo menos por quienes habrían podido concebirlas; sin desestimar la tensión que ejercen los centros de consagración que observa Jiménez, tal como se comprueba en el interés que despertaban los contactos parisinos tanto para los rioplatenses como para los venezolanos de la época.

Si bien este trabajo no me permite profundizar en el estudio de los vínculos establecidos a través del canal privilegiado que constituyeron las revistas, me interesa destacar el rol de algunos artistas que canalizaron sus vinculaciones mediante el trabajo en los consejos editoriales, como fue el caso de Lozza8, quien ya en 1946 intercambiaba correspondencia con el artista alemán Hans Platschek -radicado en Montevideo- y con Sarandy Cabrera del Taller Torres García. Algunas cartas de mediados de 1947 también dan cuenta de sus contactos con el escritor brasileño Marques Rebelo, que se suman a la circulación de su conocido artículo "Carta abierta a M. Lobato" que, luego de su aparición en el Boletín de la Asociación Arte Concreto Invención, también circuló en la revista Joaquim de Curitiba.

\section{En la trama de intercambios}

En la escena paulista la exposición 19 pintores presentada en la galería Prestes Maia en abril de 1947 fue un hito importante para la renovación9. No sólo la revista Joaquim en marzo de 1947 había reproducido el Manifiesto Invencionista -firmado en Buenos Aires en marzo de 1946-, sino que el poeta brasileño Carlos Drummond de Andrade había escrito un artículo sobre el arte concreto argentino, que circuló en diciembre de 1946 en el periódico Correio da Manhã. Con el apoyo de la União Cultural Brasil-Estados Unidos, 19 pintores reunió obras de Luiz Sacilotto, María Leontina, Geraldo de Barros y Lothar Charoux, entre muchos otros, que en esa exposición tomaron contacto con el artista italiano Waldemar Cordeiro.

Por otra parte, en este período el campo artístico brasileño estaba registrando un proceso de dinamización que contribuyó a la consolidación y difusión de las nuevas propuestas.

En 1947 el empresario del área de telecomunicaciones Assis de Chateaubriand y el marchand italiano Pietro María Bardi fundaron el Museu de Arte de São Paulo-MASP que, dentro de un perfil educativo se interesó por desarrollar el área de diseño con la creación del Instituto de Arte Contemporâneo (IAC), así como por difundir sus actividades a través de la publicación de la revista Habitat. En 1948, Francisco Matarazzo Sobrinho 
(conocido como Ciccillo Matarazzo) y Yolanda Penteado fundaron el Museu de Arte Moderna de São PauloMAM-SP, cuyo modelo de funcionamiento respondía a la línea del Museum of Modern Art de Nueva York (MoMA), institución con la que habían firmado un acuerdo de cooperación obtenido por intermedio del industrial norteamericano Nelson Rockefeller.

Para dirigir este museo fue convocado el crítico belga Léon Degand, quien al llegar a esa ciudad organizó una serie de conferencias que instalaron la problemática del arte figurativo y abstracto en el MAM-SP, mientras que el crítico argentino Jorge Romero Brest dictó varias conferencias sobre el arte contemporáneo en el MASP. Pronto, estos temas comenzaron a debatirse en la revista Artes Plásticas, donde en 1949 Cordeiro escribió el artículo "Abstracionismo", tema que también abordó junto a Charoux en la Revista de Novíssimos, de ese mismo año. Este fue el momento en el cual Dégand presentó Do Figurativismo ao Abstracionismo, que incluyó una amplia selección de artistas europeos provenientes de las galerías parisinas René Drouin y Denise René, mientras que solamente se incluyeron obras de Cordeiro, Cícero Dias y Samson Flexor de la escena local.

La dinámica del campo artístico brasileño completó el impulso aportado por los museos y las nuevas galerías dedicadas al arte moderno -como Domus fundada por Ninno Fiocca y dirigida por Alfredo Bonino- con la creación de la Bienal de São Paulo, inaugurada en octubre de 1951 que, con el tiempo, convirtió a esa ciudad en un centro artístico mundial y contribuyó a la internacionalización del arte latinoamericano.

En el mes de marzo de 1951 se había presentado en el MASP una exposición individual de Max Bill con unas sesenta obras, además de fotografías y planos, tras lo cual en la I Bienal logró el Gran Premio en Escultura para su Unidad Tripartita10. La difusión de su concepción de la forma en tanto cualidad y funcionalidad afianzó la aceptación del nuevo lenguaje y caló hondo en el perfil de los artistas concretos brasileños, que profundizaron sus indagaciones sobre la percepción visual, la teoría de la Gestalt y la integración de las artes según el proyecto de la Bauhaus.

Con respecto a la vanguardia musical, es bien conocida la proximidad entre las escenas argentina y brasileña a través de Juan Carlos Paz y Hans Joachim Koellreutter, quien en 1950 también mantuvo correspondencia con Kosice. En las cartas intercambiaron puntos de vista acerca de las correlaciones entre plástica madí y música y, además, a comienzos de 1951 el compositor alemán organizó un Curso Internacional en Teresópolis al que invitó a Maldonado, para que dictara un curso sobre Diseño Industrial (Rossi, 2007).

La llegada del arte concreto argentino a Chile se produjo en 1952 y estuvo vinculada al clima de renovación que existía en el ámbito de la arquitectura, momento en el que Josef Albers fue convocado a Santiago y Alberto Cruz Covarrubias a Valparaíso. Entre los colaboradores de Cruz se encontraba Godofredo lommi (poeta argentino interesado en el creacionismo de Vicente Huidobro y tío de los artistas concretos Claudio Girola y Enio lommi). Godofredo fue un nexo para que los argentinos presentaran la Primera Exposición de Arte Concreto, que fue exhibida en Santiago y en Viña del Mar. A pesar de que en ambas salas se presentaron con conferencia explicativas y lograron cierta repercusión, los artistas concretos revivieron las polémicas que se habían suscitado en las primeras muestras presentadas en Buenos Aires. En 1953 Girola también impulsó la difusión del Movimiento Arte Concreta (MAC) milanés que había contactado en Italia, a través de la presentación de una exposición en la galería porteña Krayd y otra en Chile. Más tarde, Girola se insertó en el ambiente cultural chileno y desarrolló desde allí el resto de su trabajo artístico. 
Para fines de 1952 los artistas paulistas presentaron la exposición Ruptura, que dio lugar a la formación de un grupo de arte concreto con este nombre, integrado por Barros, Charoux, Cordeiro, Kazmer Féjer, Leopoldo Haar, Sacilotto e Anatol Wladyslaw. En la primera muestra distribuyeron el Manifiesto Ruptura (Imagen 8) que rechazaba la intervención de la subjetividad tanto en el momento de concepción de la obra como en su realización.

Además postularon un arte como medio de conocimiento apoyado en las categorías espacio-tiempo, movimiento y materia. Las obras de esta etapa de quiebre con la tradición figurativa trabajaban sobre una calculada estructuración compositiva a partir de los elementos esenciales: la línea y el plano.

Dado que el envío argentino a la I Bienal São Paulo no llegó a destino, las obras concretas se mostraron en la II Bienal y en la exposición del Grupo de Artistas Modernos de la Argentina (GAMA) realizada en el Museo de Arte Moderno de Río de Janeiro en agosto de 1953; conjunto que, luego, viajó al Stedelijk Museum de Ámsterdam. La agrupación -que había nacido a partir de la iniciativa de Aldo Pellegrini- exhibió en el exterior con una presentación escrita por Romero Brest, quien había ganado prestigio tras su actuación como Jurado de la I Bienal. Es interesante observar que estas vinculaciones permitieron que el GAMA accediera a un centro internacional de prestigio, donde la exposición fue inaugurada con un discurso de Vordemberge-Gildewart. Sin embargo, en el marco de las negociaciones el grupo respondía a la noción de arte moderno que sostenía Pellegrini, en la cual coexistía el vocabulario geométrico -que eliminaba la huella del autor- y el libre juego de la imaginación -que acentuaba el rol de la subjetividad-, concepción que hubiera sido inaceptable para los artistas concretos en el "período heroico".

La II Bienal, dirigida por el crítico Sérgio Milliet se prolongó hasta comienzos de 1954 para coincidir con los festejos del IV Centenário de la ciudad de São Paulo y contó con la participación de treinta y tres países presentados en los pabellones diseñados por el arquitecto carioca Oscar Niemeyer en el Parque do Ibirapuera. En las salas especiales se exhibieron las obras de Paul Klee, Oskar Kokoschka, Piet Mondrian, De Stijl, Alexandre Calder, Eduard Munch, Henry Moore, James Ensor, Giorgio Morandi, Walter Gropius y Picasso. Entre diciembre de 1953 y febrero de 1954 la obra Guernica viajó desde el MoMA al MAM-SP y fue uno de los motivos del gran suceso de esa edición de la Bienal, razón por la cual se la conoce como "Bienal del Guernica".

Si bien hacia 1948 Abraham Palatnik, Ivan Serpa y Almir Mavignier habían comenzado a nuclearse en Río de Janeiro en torno a las ideas sobre la abstracción y las teorías de la percepción del crítico Mario Pedrosa, los concretos cariocas formaron el grupo Frente recién en 1954. Los artistas frentistas fueron Palatnik, Serpa, Aluísio Carvão, Carlos Val, Décio Vieira, João José da Silva Costa, Lygia Clark, Lygia Pape, César Oiticica, Franz Weissmann, Hélio Oiticica, Rubem Ludolf y Elisa Martins da Silveira, entre otros. Dentro del franco rechazo al carácter figurativo, este grupo tomó el lenguaje geométrico como un campo de expresión y experimentación. Prefirieron trabajar en el marco del respeto a la "libertad de creación" sin adoptar una única posición estilística y manteniéndose abiertos a la exploración de técnicas y materiales.

\section{Expansión del arte no figurativo}

Los primeros síntomas de apertura hacia un movimiento abstracto que desbordaba los pequeños grupos de la vanguardia concreta rioplatense -según mencionamos- fueron evidentes en las exposiciones colectivas que, ya en 1947, incluían a los concretos y madi junto a gran cantidad de artistas independientes. Pronto surgieron 
iniciativas grupales que intentaron expandir la circulación del "arte nuevo", visualizado bajo el común denominador de la ausencia de figuración, mientras se fortalecían los proyectos multidisciplinarios (que incluían las áreas proyectuales y la síntesis de las artes). Además de Madí, Perceptismo y el Grupo Joven, en los años ' 50 surgieron grupos organizados por los críticos -como el mencionado GAMA y 20 Pintores y Escultores- 0 autogestionados por los artistas, como la Asociación Arte Nuevo o Artistas no Figurativos de la Argentina (ANFA). Al riguroso vocabulario plástico de los concretos y madí, muchos de ellos fueron sumando cierta cuota de lirismo y libertad en la concepción11.

En 1952 la plástica uruguaya también tuvo su propio grupo Arte No Figurativo, donde participaron algunos de los artistas que Rothfuss había reclutado para Madí, como María Freire, Antonio Llorens, Rodolfo lan Uricchio y, por supuesto, él mismo. También integraron la nómina: Hans Platschek (que ya en 1950 habían realizado una primera exposición no figurativa), José Pedro Costigliolo, Julio Verdié, Eduardo Díaz Yepes, Washington Barcala, Marco López Lomba y Lincoln Presno, entre otros. Las exhibiciones continuaron aunque el grupo fue variando la conformación. Como los argentinos, a comienzos de los '50 los artistas enrolados en este movimiento no figurativo confrontaron con el arte constructivo universal torresgarciano (Imagen 6). Aunque ecléctica, la exposición 19 Artistas de hoy realizada en 1955 fue un resumen del arte abstracto que circulaba en Montevideo, donde se destacaron las obras más depuradas de Freire, Costigliolo, Llorens y Rothfuss. Es preciso tener en cuenta que en el panorama de la renovación uruguaya se formaron otras agrupaciones, como el Grupo La Cantera fundado en 1953 y, en 1958, el Grupo 8.

Entre 1956 y 1961 los artistas chilenos trabajaban dentro una abstracción que priorizaba la estructura, el ritmo, las formas esquemáticas y el color plano, integrando el grupo Rectángulo, formado por Elsa Bolívar, Virginia Hunneus de Vera, Matilde Pérez, Gustavo Poblete, James Smith y Ramón Vergara Grez (Imagen 15), entre otros. En general se reunían en el taller de este último artista, donde invitaban a poetas y músicos porque les interesaba debatir las posturas desde las diferentes disciplinas. Esta agrupación, constituida sobre la base del Grupo de los Cinco, más tarde, se reagrupó en el Movimiento Forma y Espacio.

"Arte no figurativo" y, tal vez, más precisamente "Arte nuevo" han sido palabras clave para titular las agrupaciones y exposiciones que encarnaron la idea de lo moderno en los diferentes escenarios del arte latinoamericano del período. En este sentido, desde julio de 1954 los artistas paraguayos también tuvieron su grupo Arte Nuevo, fundado por Josefina Plá, Olga Blinder, Lilí Del Mónico y José Laterza Parodi, aunque en este caso la propuesta incluía cierta geometrización, estilización y orientación cubo-constructivista, pero sin eludir la figuración (Quevedo, 2013). En Lima, la Agrupación Espacio fue un movimiento interdisciplinario en favor del arte moderno que, entre otros, reunió al arquitecto Luis Miró Quesada Garland, los poetas Sebastián Salazar Bondy, Jorge Eduardo Eielson, Javier Sologuren, Leopoldo Chariarse y los artistas Fernando de Szyszlo y Jorge Piqueras aunque, más que la tendencia abstracto-geométrica, según señala Augusto del Valle Cárdenas, en la escena peruana predominó la abstracción de corte lírico y gestual (del Valle Cárdenas, 2013).

Las neo-vanguardias constructivas

1. Síntesis de las artes

Uno de los aspectos centrales que planteaba el "arte nuevo" era el concepto de integración, sobre el cual disertó en Buenos Aires el arquitecto italiano Ernest Rogers, en el marco de la exposición Nuevas Realidades de 1948. 
Si bien no fueron muchos los proyectos que lograron concretarse en la época, resulta interesante mencionar la Torre alegórica (Imagen 9) construida en el acceso a la exposición Feria de América, realizada en la provincia de Mendoza en 1954. Esta torre metálica de cincuenta metros estaba formada por cinco cubos tubulares y, dentro de cada uno de ellos, se incluían dos pirámides. Funcionaba con un programa que incluía sonidos y cambios de luces, todo lo cual la convertía en una obra cinética en línea con las torres espacio-dinámicas de Nicolás Schöffer. Desarrollada por los arquitectos César Jannello y Gerardo Clusellas sobre un diseño de Maldonado, también contó con la intervención del músico Mauricio Kagel.

Si pensamos con Foster en el renovado interés por "lo constructivo" en diferentes momentos de la historia del arte latinoamericano reciente, podemos considerar a las neo-vanguardias como aquellas manifestaciones que estuvieron en condiciones de retomar el potencial transformador de las vanguardias locales, en un tiempo en el cual ya podían ser asimiladas.

Este autor analiza esa "temporalidad diferida" en la que la historia del arte se hace legible retroactivamente, a partir de la noción lacaniana de "acción diferida” (Foster, 2001).

En este sentido, cuando los integrantes de Los Disidentes regresaron a Venezuela y exhibieron sus pinturas geométricas y las esculturas abstractas estables o móviles en la Galería Cuatro Muros (fundada por Manaure y González Bogen en 1952) aún despertaron resistencias.

De hecho, escribieron un manifiesto que expresaba la intención de continuar la lucha de Los Disidentes, en procura de un arte que rechazara la figuración anecdótica a favor de la pura visualidad. Pronto fueron incluidos por Carlos Raúl Villanueva en los trabajos de la Ciudad Universitaria de Caracas, donde sus producciones quebraron los límites del circuito tradicional y se integraron en el diseño de ese moderno complejo.

Retomando la línea de pensamiento de Le Corbusier, Villanueva entendía que la integración de las artes era "el producto, no solamente de la comprensión de los propósitos comunes, sino también de la subordinación necesaria entre las distintas expresiones", es decir, era la creación de un nuevo organismo arquitectónicoescultórico-pictórico12.

Cuando en los 50 llevó adelante la segunda fase del proyecto de la Universidad, modificó algunas de las directrices de la planta e incluyó obras plásticas integradas a las funciones arquitectónicas, como las Nubes acústicas de Calder instaladas en el Aula Magna y numerosos planteos de artistas óptico-constructivos (Imagen 10).

También a partir del encargo efectuado por Daniel Mont para realizar construcciones concebidas según los desafíos de la arquitectura de vanguardia, el escultor mexicano de origen alemán Mathias Goeritz proyectó el Museo Experimental Eco en la ciudad de México.

Desde su poética, explicitada en el Manifiesto de la arquitectura emocional, propuso una estructura penetrable articulada por corredores, techos, muros y aberturas dispuestos asimétricamente y con proporciones que tienden a provocar efectos sorpresivos, porque Goeritz sostenía: "sólo recibiendo de la arquitectura emociones verdaderas, el hombre puede volver a considerarla un arte". Dentro de esta línea de trabajo, en el complejo urbanístico de Ciudad Satélite proyectado en 1954 se emplazó el conjunto escultórico Las Torres de Satélite, 
formado por cinco prismas triangulares pintados con colores planos, obra que Goeritz concibió junto al arquitecto Luis Barragán.

Bajo el dominio de la integración y con el fin de favorecer la comunicación entre las regiones y expandir la economía, en 1956 del Presidente Juscelino Kubitschek tomó la decisión de construir Brasilia en el centro del país. Para la concreción del proyecto Novacap se realizó un concurso de ideas en el que fue seleccionado un proyecto apenas bocetado por Lúcio da Costa. Una vez llevado a etapa ejecutiva, ese Plano Piloto de Brasilia fue construido en tiempo record (aproximadamente tres años) por un equipo de arquitectos entre los cuales participó Oscar Niemeyer y, en el paisajismo, Roberto Burle Marx. Obras como la Catedral, el Palacio de Itamaray, las Cámaras de Diputados y Senadores (Imagen 11), entre otras, conjugaron el programa corbussiano (pilotes, planta y fachada libre, balcón-jardín y grandes ventanales) y la idea de invención de nuevas formas arquitectónicas, interpretadas por Niemeyer con la libertad presente en el barroco americano y construidas según las posibilidades plásticas del hormigón armado.

\section{Op-art y Cinetismo desde París}

Los trabajos ópticos de Víctor Vasarely y el entorno de la galería parisina de Denise René fueron un polo de atracción para los artistas latinoamericanos interesados por incorporar el movimiento y el rol activo del espectador a sus obras de cuño constructivo. Uno de los primeros jóvenes venezolanos en viajar a París fue Otero que, luego de reducir la figura a líneas en la serie Las cafeteras ya mencionada, continuó el camino hacia los trabajos con trazos de color sobre fondos muy luminosos y, luego, desembocó en sus Colorritmos, cuyos sistemas lineales permiten entrever otras formas y generan efectos vibratorios.

En los primeros días de octubre de 1950 llegó a París Jesús Rafael Soto, quien ayudado por sus amigos venezolanos, especialmente, por la pintora Aimée Battistini (oriunda de Ciudad Bolívar donde también había nacido él) frecuentó Denise René y asistió al Atelier d’Art Abstrait, donde conoció a los principales teóricos del arte abstracto. En ese ambiente se interesó por experimentar con los desplazamientos de sistemas lineales y la interposición de pantallas o tramas y, en 1955, participó en Lumière et Mouvement junto a Marcel Duchamp, Alexander Calder, Jean Tinguely y entre otros.

En 1956 se estableció en París el argentino Antonio Asís, quien se interesó por las vibraciones y, en los primeros tiempos, asistió a Soto en la preparación de sus muestras internacionales.

Al año siguiente Luis Tomasello también ingresó en ambiente de Denise René, y en 1958 arribaron Vardánega y Martha Boto, quienes caracterizaron su obra cinética por las reflexiones coloreadas.

Desde finales de los '50 Carlos Cruz Diez indagó las posibilidades del color trabajado a partir de series lineales programadas en sus Fisicromías. Más tarde, se concentró sobre el color en el espacio y en el tiempo hasta llegar a las Cromo-saturaciones, (Imagen 14) entre las que realizó cabinas de acrílico transparente y cámaras que generan situaciones monocromáticas que afectan la percepción del color. También trabajaron en París los chilenos Iván Contreras Brunet -interesado en las vibraciones provocadas por tramas metálicas-y Matilde Pérez, quien recibió una beca del Gobierno francés en 1960 que la puso en contacto con Vasarely, tras lo cual se interesó por el movimiento virtual y, desde 1970, aplicó mecanismos para lograr el movimiento real. 
Para el contacto de los jóvenes del Cono Sur con este artista húngaro resultó clave su exposición que en 1958 recorrió los museos de Buenos Aires, Montevideo y San Pablo, auspiciada por la galería Denise René. Al impacto de las cuarenta obras del período blanco y negro de Vasarely, se sumó el estímulo de las teorías de la pura visibilidad y de la Gestalt que circulaban en los centros de formación artística. Esta línea de intereses abrió una vía de experimentación sobre la percepción visual y la dinámica de la forma y el color que, entre los argentinos, generó desarrollos colectivos -como en el caso del Arte Generativo practicado por Eduardo Mac Entyre y Miguel Ángel Vidal, así como el trabajo de muchos artistas que actuaron individualmente en el país (entre ellos: Rogelio Polesello, Manuel Espinosa, Ary Brizzi, Eduardo Rodríguez, César Fioravanti y Perla Benveniste).

Son bien conocidos los desarrollos de los argentinos en París a través del Groupe de Recherche d'Art Visuel (GRAV), (Imágenes 12 y 13) formado por Julio Le Parc, Horacio García Rossi, Francisco Sobrino, François Molnar, François Morellet, Joël Stein y Jean-Pierre Yvaral, quienes insistieron en poner en evidencia tanto la inestabilidad visual como el tiempo de la percepción y, pronto, apelaron a la participación activa de los espectadores en recorridos, que llamaron Laberinto, como el presentado en la Bienal de París de 1963. En los años '60, tanto el GRAV como los latinoamericanos que trabajaban individualmente en París integraron la Nouvelle Tendence-Recherche Continuelle, agrupación en la que se contaron Hans Haaker, Enrico Castellani, Enzo Mari y los colectivos Equipo 57 de España, Grupos N de Padua y T de Milán.

\section{Neo-concretismo brasileño}

En el caso brasileño, en 1956 se organizó la I Exposição Nacional de Arte Concreta realizada en el MAM-SP, que en febrero de 1957 fue presentada en el Ministerio de Educación y Cultura en Río de Janeiro. Este panorama del arte concreto hizo evidente las diferencias entre el grupo paulista Ruptura (Imagen 8) y el carioca Frente. Por un lado los paulistas exhieron el más alto nivel alcanzado por el arte concreto brasileño e incluyeron a la poesía concreta, a través del trabajo del grupo Noigandres formado por Décio Pignatari y Haroldo y Augusto de Campos, cuyos poemas valorizaban el espacio de la página y jugaban con los recursos tipográficos, en diálogo con las artes visuales. Por otro lado, los frentistas entraron en una fase de replanteo y cuestionamientos que los llegó a disgregar al grupo; no obstante, en poco tiempo surgió un proceso de reagrupamiento que dio lugar al Movimiento Neoconcreto.

En este sentido, en marzo de 1959 se inauguró la I Exposição de Arte Neoconcreta en el MAM-RJ con la distribución del Manifiesto Neoconcreto. En los planteos de este movimiento, la teoría fue surgiendo de la reflexión sobre las obras creadas, porque se basaron más en la intuición que en los preceptos. Uno de los ejes del trabajo de este grupo fue la búsqueda de participación del espectador, que puede rastrearse en hasta los libros-poema que Ferreira Gullar creó en 1959 y los poemas-objeto construidos en madera que obligaban a tocarlos para descubrir la palabra, vía que condujo a los objetos relacionales que no sólo involucraban la participación manual sino también corporal (Ferreira Gullar, 1998).

La siguiente ruptura se fue dando a través del abandono de los materiales y prácticas habituales del pintor, como en el caso de Clark que cambió el lienzo por madera y la rellenó con pintura para crear los Capullos y, en 1960, trabajó con planchas de metal para crear objetos tridimensionales que llamó Bichos, cuyas articulaciones permiten modificar la conformación permanentemente. En el caso de Oiticica cambió el bastidor por placas de madera superpuestas para generar Relieves espaciales, Núcleos que consistían en laberintos abiertos de 
paneles colgantes con gradaciones de color y, luego, Bólides que presentaban cajas de madera o de vidrio en las que el espectador era invitado a manipular el color contenido en diferentes formas. En su caso, estas rupturas continuaron con el quiebre más radical que supuso el abandono de la idea de objeto-obra para convertirse en provocador de sensaciones mediante las acciones con sus Parangolés (vestidos de color usados en las performances). Este tipo de obras fue de-construyendo la tradición del cuadro de caballete para llegar a crear un nuevo objeto, tratado por Ferreira Gullar como no-objeto precisamente en su Teoría del no-objeto anticipada en 1959.

\section{El retorno de las prácticas: los casos de Forma y Espacio y Groupe Position}

La pulsión internacionalista del arte moderno instaló en las agendas de los países latinoamericanos la necesidad de incursionar en nuevos circuitos tensados por relaciones asimétricas.

Al mismo tiempo, los centros de poder también manifestaron interés por los acercamientos -no exentos de otros tantos intereses políticos y económicos- como en el caso de las iniciativas articuladas desde el programa estadounidense de la Alianza para el Progreso.

En Latinoamérica desde los '50 la Bienal de São Paulo actuaba como nodo configurador de las nuevas relaciones internacionales, y a finales de la década surgieron algunas fundaciones o empresas privadas que financiaron polos que dieron cabida a las vanguardias, como el Instituto General Electric en Montevideo, las Bienales Americanas de Arte en Córdoba y el Instituto Torcuato Di Tella (ITDT) en Buenos Aires, entre otras. En este último, el arte constructivo tuvo su espacio dentro el efervescente clima del Centro de Artes Visuales dirigido por Romero Brest, quien en 1967 realizó la curaduría de Más allá de la geometría, un panorama evolutivo que explicaba el pasaje del cuadro-escultura al objeto, en un proceso que incluía desde el movimiento y la desmaterialización hasta las estrategias minimalistas. Ese mismo año, se organizó la Semana de arte avanzado, actividad que sumó exhibiciones paralelas en varias instituciones, entre las que se destacó la presentación de estructuras primarias13.

Al año siguiente el Center for Inter American Relation invitó a Romero Brest a celebrar en Nueva York el décimo aniversario de Centro de Artes Visuales, ocasión en la cual el ITDT estuvo representado por Beyond Geometry, esta vez con una selección aggiornada en la cual tuvieron preeminencia a las estructuras primarias, cuyos volúmenes geométricos netos pintados con colores planos "retomaban" el repertorio del arte concreto desde la lógica de la simplicidad, la repetición y el orden.

Precisamente, en un análisis retrospectivo Romero Brest escribió que su selección llevaba implícita una inquietud con relación a la geometría y el orden, que le había surgido en los años '50 al regresar de Grecia. Reeditada frente al arte constructivo, aquella inquietud le abría un interrogante: "siendo los argentinos "tan románticos como desordenados”, ¿por qué esta adhesión a la geometría?”. Según su opinión, la gran difusión de esa tendencia entre los argentinos se debía a que las formas geométricas obedecen a "una escondida pedagogía, la de la Paideia de los griegos, y que éstas suelen ser recurso de los que temen sus propios arrebatos". Esta suerte de instrumentalización del vocabulario constructivo explicaría, también, la estratégica elección de Beyond Geometry para representar al ITDT, una exposición funcional al discurso de los anfitriones que, en esos días, temían el avance de los movimientos de guerrilla y la radicalización de las izquierdas latinoamericanas. 
También los artistas neo-vanguardistas "repitieron" los esfuerzos que había realizado la vanguardia para intervenir en el dominio de una Institución que tendía a excluirlos. Entre muchos, los casos de Forma y espacio y el Groupe Position testimonian este tipo de iniciativas.

El primero corresponde a la intervención sobre los espacios de difusión y legitimación, ya que a partir de la $1^{\text {a }}$ Muestra Internacional "Forma y Espacio", organizada en 1962 por la Universidad de Chile -con la asesoría de Vergara Grez- los artistas firmaron el Manifiesto de los pintores constructivos de Argentina, Chile y Uruguay, que finalizaba expresando: "para afrontar el momento presente, acordamos mantener unidos nuestros esfuerzos en un frente de artistas constructivos, que facilite el intercambio de ideas, investigaciones, experiencias o puntos de vista"14. Además, resolvieron darle carácter permanente al grupo y realizar el próximo encuentro en la Argentina, para lo cual nombraron una comisión organizadora que decidió que en la "Bienal", se incluirían esculturas en movimiento. Sin embargo, aunque los artistas emprendieron la organización y lograron avances significativos, los encuentros bienales nunca lograron concretarse.

El segundo caso se relaciona con la inserción en el circuito de difusión y comercialización, ya que tras la disolución del GRAV los artistas argentinos García Rossi, Horacio Demarco, Antonio Asís, Leopoldo Torres Agüero y Armando Durante formaron el Groupe Position (Imagen 16), que salió a escena con un manifiesto que señalaba: "En abril de 1971 nos decidimos a formar el grupo en vista de lo difícil que resulta la lucha individual del artista en una sociedad que lo margina" 15 y, con el fin de dinamizar la circulación se propusieron compartir la financiación y la organización de exposiciones, crear un fondo común proveniente de las ventas para financiar un taller para uso común y para mostrar obras, así como realizar investigaciones en común y reuniones periódicas de crítica de obra. Este modo de funcionamiento les permitió trazar un buen recorrido de exhibiciones entre Bruselas, Brescia, Madrid, Sevilla, aunque después de realizar una exitosa muestra en Zurich, el grupo se dispersó.

Ambos casos muestran el retorno táctico a las prácticas de la vanguardia en el marco de complejización del sistema, aunque estas "recuperaciones tácticas" podrían pensarse -siguiendo a Michael de Certeau-como "trucos" del débil que intenta quebrar el orden construido, aunque sus historias de resistencias vuelven al punto de partida.

\section{A modo de conclusión}

Aún teniendo en cuenta que los límites del presente trabajo exigieron considerar sólo los principales puntos de desarrollo del arte constructivo en Latinoamérica16, este primer mapeo permite visualizar rupturas y continuidades. Es cierto que los relatos tradicionales celebraron que el arte concreto rioplatense fue simultáneo al europeo de posguerra (que había interrumpido o alterado sus desarrollos debido a las acciones bélicas); $\sin$ embargo, tendieron a valorar más esa sincronía, que a "situar" esa irrupción vanguardista para explicar las "repeticiones" según propone hacer Hal Foster (2001, p. 3-36).

Desde mi enfoque, considero que la apuesta por la racionalidad en tiempos de devastación debe analizarse teniendo en cuenta la situación geopolítica del área rioplatense, porque fue la distancia de aquellos escenarios destruidos por la guerra, la que generó las condiciones de posibilidad para el surgimiento de programas estéticos que se anticipaban al tiempo de la reconstrucción. Pero, además, desde una perspectiva marxista estos programas suponían una transformación radical que, por un tiempo, los artistas concretos creyeron 
posible. Tras la declinación de ese impulso utópico, comenzó una etapa de consolidación y expansión del lenguaje de un "arte nuevo" de base constructiva.

En este sentido, el mapeo de los proyectos que surgieron en América Latina a la salida de la guerra muestra cómo se fueron reactivando las estrategias de las vanguardias, cómo se vincularon artistas y propuestas en el proceso de conformación de los nuevos programas y, al mismo tiempo, permite observar las plataformas comunes, como el caso del estancamiento de los sistemas locales de formación artística y las disconformidades de los más jóvenes dispuestos a quebrar el status quo. La posibilidad de situar históricamente la emergencia de las repeticiones de las vanguardias constructivas -en términos de Foster- invita a valorar sus revisiones, despliegues y re-codificaciones. No obstante, la creciente complejidad del sistema artístico y la lógica de la economía mundial constituyen retos permanentes para las producciones latinoamericanas.

\section{Notas}

1. Si bien los acuerdos de la Conferencia Panamericana de Panamá crearon una zona oceánica de protección que incluía los Estados Unidos y Latinoamérica, a los tres meses de su firma se desató la batalla naval angloalemana de Punta del Este y, más tarde, Estados Unidos se involucró en la contienda. La Conferencia de La Habana de 1940 autorizó la actuación -en caso de urgencia- sin recurrir al proceso de consulta; medida que abrió una posibilidad para que los norteamericanos colocaran bases navales en posesiones británicas, en Brasil y en la Guayana holandesa. En la reunión realizada en Río de Janeiro en 1942, se reactivaron los mecanismos panamericanos pero, debido a la resistencia de los argentinos y chilenos, sólo se llegó a la recomendación de la ruptura de relaciones con el Eje. Chile demoró un año esta decisión, mientras que la Argentina recién la adoptó en enero de 1944.

\section{En el "Manifiesto n 2. Constructivo 100\%" de diciembre de 1938 Torres García escribió: "El constructivismo} fue. Nadie piense en él. Su propio divulgador ya no se ocupa más en insistir con sus conferencias. Al fin pasó tal cosa molesta!" 3. En octubre y noviembre de 1945 se organizaron las veladas del Movimiento de Arte Concreto Invención en las residencias particulares de Enrique Pichón Rivière y Grete Stern, mientras que Claudio Girola, Alfredo Hlito, Enio lommi, Raúl Lozza, Tomás Maldonado y Lidy Prati realizaron una primera reunión para exhibir sus producciones en noviembre de 1945 en el taller de la calle San José 1557.

4. En la primera exposición de la AACI participaron Bayley, Antonio Caraduje, Simón Contreras, Espinosa, Claudio Girola, Hlito, Iommi, Obdulio Landi, Raúl Lozza, Rembrand Van Dyck Lozza, Maldonado, Alberto Molenberg, Mónaco, Oscar Núñez, Prati y Jorge Souza y, luego se sumaron Juan Melé, Virgilio Villalba y Gregorio Vardánega.

5. En la primera exposición Madi participaron Arden Quin, Gyula Kosice, Rhod Rothfuss, Diyi Laañ, Elizabeth Steiner o Esteban Eitler, Martín Blaszko, Valdo W. Longo, Ricardo Humbert, Alejandro Havas, Dieudonné Costes, Raymundo Rasas Pét, Sylwan Joffe Lemme y Paulina Ossona (algunos nombres corresponden a seudónimos de los integrantes estables).

6. Situaciones semejantes debieron afrontar el poeta Elio Vittorini en Italia tras la fuerte polémica desatada con Palmiro Togliatti, el crítico belga Léon Degand que perdió su columna en Les Lettres Françaises, mientras que 
en la URSS se le exigió a Serguei Prokofiev ajustarse al realismo socialista porque su música fue considerada formalista.

7. Cf. Catálogo exposición José Mimó Mena y el grupo concreto invención de Buenos Aires, Taller Libre de Pintura, Caracas, 24-10-48.

8. Integrante del colectivo editorial de Contrapunto, Arte Concreto y Perceptismo. Teórico y polémico.

9. Esta exposición también registra el antecedente del Salão de Maio de los años '30.

10. M. Amalia García ha demostrado que esta muestra, citada por la mayor parte de la bibliografía en 1950 , recién se inauguró el 1 de marzo de 1951 (García, 2011).

11. Debido a la extensa lista de artistas que intervinieron remito a mi estudio Jóvenes y modernos de los años 50 (Rossi, 2012), realizado sobre la base de los trabajos grupales.

12. Carlos Raúl Villanueva. “El problema de la integración” (Jiménez, Ed., 2009:196-8).

13. La muestra Estructuras Primarias. Jóvenes escultores estadounidenses y británicos se había presentado en el Jewish Museum de Nueva York sólo un año antes.

14. "Manifiesto de los pintores Constructivos de Argentina, Chile y Uruguay", septiembre de 1962.

15. Cf. Grupo Posición, dactiloscrito, Archivo Leopoldo Torres Agüero.

16. La extensión de este trabajo no ha permitido tratar algunos casos, como la vertiente americanista del arte constructivo, o la labor de importantes artistas como el boliviano Oscar Pantoja, los mexicanos Manuel Felgueres o Vicente Rojo, el colombiano Omar Rayo, entre muchos otros.

\section{Bibliografía}

Amaral, A. (Ed.). (1998). Arte constructivo no Brasil, Coleçao Adolpho Leirner. São Paulo: Companhia Molhoramentos - DBA Aguilar, G. (2003). "De la Bienal a Brasilia”, en Aguilar, G., Poesía concreta brasileña: las vanguardias en la encrucijada modernista, Buenos Aires: Beatriz Viterbo, pp. 51-92.

Belluzzo, A. M. (1998). "Ruptura e Arte Concreta”, en Amaral, A. (Coord.) Arte Construtiva no Brasil. Coleção Adolpho Leirner. São Paulo: Companhia Melhoramentos, pp. 95-141.

Bourdieu, P. (1995). Las reglas del arte. Génesis y estructura del campo literario. Barcelona: Anagrama.

Certeau, M. de (2001). “De las prácticas cotidianas de oposición”, en Modos de hacer: arte crítico, esfera pública y acción directa. Salamanca: Ediciones Universidad de Salamanca, pp. 391-425.

Crispiani, A. (2011). Objetos para transformar el mundo. Trayectorias del arte concretoinvención, Argentina y Chile, 1940-1970. Bernal: Editorial de la Universidad Nacional de Quilmes/ Prometeo. 
Cruz Diez, C., Jiménez, A. (2010). En conversación, Nueva York: Fundación Cisneros.

Del Valle Cárdenas, A. (2013) “La invención de una tradición: La pintura abstracto-geométrica en Perú (19481958)", en Hueso Húmero, nº60. Lima: Mosca Azul.

Escobar, T. (2004). El arte fuera de sí. Asunción: FONDEC-CAV/Museo del Barro.

Ferreira Gullar. "O Grupo frente e a reação Neoconcreta”, en Amaral, A. (Coord.) ArteConstrutiva no Brasil. Coleção Adolpho Leirner. São Paulo: Companhia Melhoramentos, pp. 143-181.

Foster, H. (2001) El retorno de lo real. La vanguardia a finales de siglo. Madrid: Akal.

García, M. A. (2011). El arte abstracto. Intercambios culturales entre Argentina y Brasil. Buenos Aires; Paidós.

Giunta, A. (2013). “Adiós a la periferia. Vanguardias y neovanguardias en el arte de América Latina”, en La invención concreta. Colección Patricia Phelps de Cisneros. Reflexiones en torno a la abstracción geométrica latinoamericana y sus legados. Madrid: Museo Centro de Arte Reina Sofía, pp. 104-117.

Ivelic, M. y Galaz, G. (1988). Chile, arte actual. Santiago de Chile: Ediciones Universitarias de Valparaíso.

Jiménez, A. (Ed.). (2009). "A la altura de los tiempos, 1949-1974”, en Jiménez, Ariel, Alfredo Boulton y sus contemporáneos. Diálogos críticos en el arte venezolano 1912-1974. Caracas: Fundación Cisneros - Nueva York: The Museum of Modern Art. pp. 156-321.

Lizama, P. (s-f). "Huidobro y la vanguardia de los treinta”. Disponible en: http://www.vicentehuidobro.

uchile.cl/ensayo_patricio_lizama.htm (consultado 20 de agosto de 2014).

Medina, A. (2012). "Abstracción y geometría en el arte colombiano". En Arte al Día International, n 140, Miami, pp. 92-9.

Melé, J. (1999). La vanguardia del cuarenta en la Argentina. Memorias de un artista concreto. Buenos Aires: Ediciones Cinco.

Peluffo Linari, G. (2006). Historia de la pintura uruguaya. Tomos 1 y 2. Montevideo: Banda Oriental [1985-87].

Quevedo, Ch. (2013). “La Misión Cultural Brasileña y el grupo Arte Nuevo. Disputas regionales por la hegemonía cultural e inscripción de la modernidad artística paraguaya", mimeo.

Rodríguez, B. (1979). Arte Constructivo Venezolano 1945/65. Génesis y Desarrollo, Caracas: GAN.

Rodríguez Prampolini y Ferruccio Asta (Comp). (1997). Los ecos de Mathias Goeritz. Ensayos y testimonios. México D.F.: Museo de San Ildefondo, Centro Nacional de las Artes.

Rossi, C. (2007). "Vanguardia concreta rioplatense. Acerca del arte concreto y la música”, en ICAA Document Project Working Papers, $n^{\circ} 1$, Houston: International Center for the Arts of the Americas at the Museum of Fine 
Arts, pp. 11-24.

Rossi, C. (2009). "Pasos cordilleranos. Intercambios argentino-chilenos alrededor del arte abstracto", en Transnational Latin American Art from 1950 to the Present Day International Research Forum for Graduate Students and Emerging Scholars. Austin: University of Texas at Austin.

Rossi, C. (2010). “Escritos y testimonios. El caso del 'Manifiesto de cuatro jóvenes”', en VII Jornadas Nacionales de Investigaciones en Arte en Argentina. Los desafíos del arte en el año del Bicentenario". La Plata: Facultad de Bellas Artes, UNLP, CD Rom.

Rossi, C. (2012). Jóvenes y modernos de los años '50. En diálogo con la colección Ignacio Pirovano. Buenos Aires: Museo de Arte Moderno.

Schwartz, J. (2002). Brasil 1920-1950. Da Antropofagia a Brasília. São Paulo: Museu de Arte Brasileira da Fundação Armando Álvares Penteado.

Wilson, A. (2007). Consonancia. La abstracción geométrica en la Argentina y Venezuela. Años 40 y 50. Caracas: Artesanogroup.

Abstract:

Constructive art projects that emerged in Latin America since the immediate postwar period were forming a dense network of contacts, which shows common platforms such as the case of stagnation of local artistictraining systems, and invites to explore exchanges between artists and characteristics with which the avant-garde strategies were reactivated in different scenes. Redraw the plot, then, helps to visualize ruptures and continuities. Also, within the limits imposed by this mapping, the article make a review of some cases that reflect the challenges of Latin American artists productions in the context of the increasing complexity of the art system and the logic of globalization of capital.

Key words:

latin American art - constructive art - concrete art - non figurative art - new art - geometric abstraction - vanguard/ new vanguard - kinetic art - art integration.

Abstract:

Os projetos de arte construtivo que surgiram na América Latina desde a imediata pôs guerra conformaram uma densa rede de contatos, que mostra plataformas comuns -como o caso do estancamento dos sistemas locais de formação artística-, e convida a explorar intercâmbios entre artistas e as particularidades com as que se reativaram as estratégias das vanguardas em diferentes cenas. Re-desenhar essa trama, então, permite visualizar rupturas e continuidades. Além disso, se revisam alguns casos que refletem os retos aos que estão submetidas as produções dos artistas latino-americanos no marco da crescente complexidade do sistema artístico e da lógica da globalização do capital.

Palavras chave: 
arte latino-americana - arte construtiva - arte concreta - arte não figurativa - arte nova - abstração geométrica vanguarda / Neo-vanguarda - cinetismo - integração das artes.

Redes latinoamericanas de arte constructivo fue publicado de la página 103 a página125 en Cuadernos del Centro de Estudios de Diseño y Comunicación № 60 